\title{
Produção e vigor da videira 'Niágara Rosada' relacionados com o porta-enxerto(1)
}

\author{
Dário Pauletto ${ }^{(2)}$, Francisco de Assis Alves Mourão Filho(3), Ricardo Alfredo Kluge ${ }^{(4)}$ \\ e João Alexio Scarpare Filho(5)
}

\begin{abstract}
Resumo - Avaliou-se a produção e o vigor da videira 'Niágara Rosada' sobre os porta-enxertos 'IAC 313', 'IAC 766', 'Kober 5BB', 'Traviú' (106-8 Mgt) e 'Schwarzmann', no período de 1990 a 1998, em Taubaté, SP. As maiores produções médias foram obtidas quando se utilizaram os porta-enxertos 'IAC 313' e 'IAC 766', totalizando 2,69 kg/planta e 2,59 kg/planta, respectivamente. As produções alcançadas com os porta-enxertos 'Kober 5BB' e 'Schwarzmann' foram, em média, 110\% menores que os anteriores, enquanto o 'Traviú' apresentou comportamento intermediário. Os porta-enxertos 'IAC 313' e 'IAC 766' também induziram maior vigor à copa, representado pela maior massa de ramos podados e maior diâmetro das plantas. Para a formação de um vinhedo com 'Niágara Rosada', recomenda-se, para a região, os porta-enxertos 'IAC 313', 'IAC 766' ou 'Traviú'.
\end{abstract}

Termos para indexação: Vitis labrusca, propagação vegetativa, enxertia.

\section{Yield and plant vigor of 'Niágara Rosada' grape vine related to the rootstock}

\begin{abstract}
The yield and plant vigor of 'Niágara Rosada' grafted on the 'IAC 313', 'IAC 766', 'Kober 5BB', 'Traviú' (106-8 Mgt) and 'Schwarzmann' rootstocks were evaluated from 1990 to 1998 , in Taubaté, SP, Brazil. The highest average yields were obtained on the 'IAC 313' and 'IAC 766' rootstocks, reaching $2.69 \mathrm{~kg} / \mathrm{plant}$ and $2.59 \mathrm{~kg} / \mathrm{plant}$, respectively. Yields on 'Kober 5BB' and 'Schwarzmann' were $110 \%$ smaller than on the previous ones, while 'Traviú' showed intermediary behavior. 'IAC 313' and 'IAC 766' also induced higher vigor in the vine, represented by higher mass of pruned branches and higher diameter of plant. 'Niágara Rosada' cultivation in the region is recommended on the 'IAC 313', 'IAC 766' or 'Traviú' rootstocks.
\end{abstract}

Index terms: Vitis labrusca, vegetative propagation, grafting.

\section{Introdução}

As condições fundamentais exigidas para um bom porta-enxerto, em viticultura, incluem resistência a filoxera e nematóides, adaptação ao ambiente, facilidade de propagação, afinidade satisfatória com as cultivares copa, e sanidade (Hidalgo, 1993).

\footnotetext{
(1) Aceito para publicação em 8 de março de 2000. Apoio financeiro FAPESP.

(2) ESALQ, Caixa Postal 9, CEP 13418-900 Piracicaba, SP. Bolsista da FAPESP.

(3)ESALQ, Dep. de Produção Vegetal. Bolsista do CNPq. E-mail: famourao@esalq.usp.br

(4)ESALQ, Dep. de Ciências Biológicas.

E-mail: rakluge@carpa.ciagri.usp.br

${ }^{(5)}$ ESALQ, Dep. de Produção Vegetal.
}

A relação enxerto/porta-enxerto em viticultura é avaliada por diversas interações e respostas no potencial vegetativo e produtivo das plantas, bem como na qualidade dos frutos (Pastena, 1981). Tem sido verificado que videiras enxertadas apresentam maior produção do que videiras de pé-franco. Segundo Edwards (1988), isto pode ser explicado pelo fato de que os porta-enxertos conferem uma alta densidade de raiz e maior vigor à copa, se comparados ao pé-franco. Além disso, plantas enxertadas antecipam a produção, uma vez que na região em que foi realizada a enxertia ocorre um relativo estrangulamento à passagem de seiva nos dois sentidos, podendo promover aumento na relação carbono/nitrogênio na copa (Faust, 1989; Hartmann \& Kester, 1990).

Atualmente, inúmeras cultivares de porta-enxertos encontram-se disponíveis aos viticultores. Entretanto, cada uma delas apresenta vantagens e defi- 
ciências, e só com a experimentação pode-se determinar com regular precisão qual a mais adequada para determinada região (Pommer et al., 1997).

Martins et al. (1981), estudando o comportamento da cultivar de uva de mesa Patrícia (Vitis spp.) sobre os porta-enxertos 'Traviú', 'RR 101-14', 'Kober 5BB', 'IAC 313', 'IAC 766', em Jundiaí, SP, verificaram as maiores produções com o 'IAC 766' e 'Traviú', seguidos pelo 'IAC 313' e '101-14', e, finalmente, 'Kober 5BB', que apresentou a menor produção.

Terra et al. (1988) investigaram vários porta-enxertos e sua influência na produção e qualidade dos frutos de videiras 'Niágara Rosada', durante o período de 1975 a 1983, em Jundiaí. A maior produção foi obtida em plantas enxertadas sobre 'Schwarzmann', não tendo diferido das produções obtidas nos porta-enxertos 'Golia', 'Traviú', 'IAC 572' e '571-6'.

Terra et al. (1989), em Jundiaí, estudaram o comportamento de duas cultivares de uva tipo moscatel para vinho, IAC 21-14 e IAC 931-13, sobre os porta-enxertos 'RR 101-14', 'Kober 5BB', 'Traviú', 'IAC 313' e 'IAC 766'. Os autores averiguaram que as maiores produções médias da cultivar IAC 21-14 foram obtidas quando se utilizaram os porta-enxertos 'IAC 766' e 'Traviú', seguidos do 'RR 101-14' e 'IAC 313'.

Em experimento desenvolvido em Monte Alegre do Sul, SP, Terra et al. (1990a) avaliaram o comportamento da cultivar IAC 138-22 (máximo) sobre cinco porta-enxertos ('RR 101-14', 'Golia', 'Traviú', 'IAC 572' e 'IAC 313') entre os anos agrícolas de 1974 e 1981. Observaram que o 'IAC 572' induziu as maiores produções para a cultivar copa estudada.

Nos Municípios de Tietê e Tatuí, SP, Terra et al. (1990b) estudaram o comportamento de quatro híbridos IAC para produção de vinho ('IAC 138-22', 'IAC 960-9', 'IAC 116-31' e 'IAC 960-12'), tanto produtores diretos, quanto enxertados sobre 'IAC 313', 'IAC 766' ou 'Traviú'. Constataram que, no conjunto dos ambientes (anos e locais), as maiores produções foram obtidas com as cultivares IAC 138-22 e IAC 960-9 enxertadas sobre o portaenxerto 'IAC 766'. Nas condições de Tietê, essas cultivares copas, enxertadas sobre o 'IAC 766', apresentaram potencial produtivo semelhante ao obtido sobre o 'IAC 313'.
Abrahão et al. (1996), na região de Caldas, MG, avaliaram o comportamento da cultivar Folha-de-figo (Vitis labrusca L.) sobre cinco porta-enxertos e em pé-franco. As maiores produções foram obtidas sobre 'IAC 313' e 'IAC 766' (2,69 e 2,57 kg/planta, respectivamente), ao passo que com o porta-enxerto 'RR 101-14' foi verificada produção de 2,17 kg/planta. Os porta-enxertos 'Jacquez' e 'Kober 5BB', e o pé-franco produziram 1,63, 1,31 e 1,55 kg/planta, respectivamente.

Em Caldas, Gonçalves et al. (1999) estudaram o comportamento dos porta-enxertos 'Kober 5BB', 'IAC 313', 'RR 101-14' e 'Jacquez' sobre a produção de uvas 'Folha-de-figo'. Os autores verificaram que o 'IAC 313', o 'RR 101-14' e o 'Jacquez' promoveram as maiores produções.

O Vale do Paraíba, no Estado de São Paulo, é uma região onde as condições edafoclimáticas favorecem a prática da viticultura, desde que sejam selecionadas para essa região combinações de copa e porta-enxerto, e definido o manejo mais adequado da cultura.

O objetivo deste trabalho foi avaliar o comportamento de cinco porta-enxertos para a videira 'Niágara Rosada' nas condições de Taubaté, SP.

\section{Material e Métodos}

O experimento foi iniciado em 1989, na área experimental do Departamento de Ciências Agrárias da Universidade de Taubaté, em Taubaté, SP, com altitude do local de $600 \mathrm{~m}$, a latitude de $22^{\circ} 54^{\prime}$ e longitude $45^{\circ} 33^{\prime}$, num Latossolo Vermelho-Amarelo álico e clima classificado como Cwa.

$\mathrm{O}$ vinhedo foi conduzido em espaldeira com três fios de arame e regime de poda curta em duas gemas sobre cordão esporonado.

Os tratamentos consistiram da combinação da cultivar Niágara Rosada sobre os porta-enxertos 'IAC 313'; 'IAC 766'; 'Kober 5BB'; 'Traviú' e 'Schwarzmann'. As principais características desses porta-enxertos serão descritas a seguir:

'IAC 313' ('Tropical'): foi obtido por Santos Neto, em 1950, citado por Pommer et al. (1997) a partir do cruzamento do porta-enxerto Golia com a espécie Vitis smalliana. É um porta-enxerto vigoroso, adapta-se bem a diferentes tipos de solo, é pouco afetado por doenças da parte aérea e suas estacas apresentam bom índice de enraizamento. Está bem adaptado às condições quentes 
do Estado de São Paulo, e no Submédio São Francisco é um dos porta-enxertos mais utilizados. Apresenta boa afinidade com videiras 'Itália,' 'Rubi', 'Patrícia', 'Benitaka', 'Red Globe', 'Paulistinha, 'IAC 138-22', 'Isabel' e outras (Pommer et al., 1997).

'IAC 766' ('Campinas'): originou-se do cruzamento entre o porta-enxerto 'Traviú' e Vitis caribaea, realizado por Santos Neto (1958), citado por Pommer et al. (1997). Santos Neto (1973) afirmou que esse porta-enxerto é um dos mais indicados para uvas finas de mesa. Trata-se de um porta-enxerto vigoroso; o enraizamento das suas estacas é satisfatório; apresenta boa resistência às doenças. É considerado um adequado porta-enxerto para as cultivares Itália, Rubi, Benitaka, Red Globe, Patrícia, Maria, Paulistinha e Niágara. Por sua adaptação, vem sendo bastante utilizado no Estado de São Paulo (Sousa, 1996; Pommer et al., 1997).

'Kober 5BB': proveniente do cruzamento entre $V$. berlandieri e V. riparia, realizado por Teleki e selecionado por Kober, na Áustria, no início deste século. Revela vigor médio, adapta-se bem a diferentes tipos de solo, desde que não sejam excessivamente ácidos; é resistente à seca e às doenças fúngicas; apresenta satisfatório enraizamento das estacas, e seu ramos mostram lignificação tardia. Possui afinidade com videiras 'Itália' e 'Rubi', embora se observe, freqüentemente, um engrossamento do tronco acima do ponto de enxertia, indicando, assim, falta de vigor do porta-enxerto em relação à copa (Pommer et al., 1997). Simão (1998) comenta que pode haver problemas de afinidade com muitas cultivares, corroborando Nogueira (1984) que verificou o mesmo, incluindo a Niágara Rosada.

'Traviú' ('Ripária do Traviú'): trata-se de um híbrido entre $V$. riparia $\mathrm{x}(V$. rupestris $\times$ V . cordifolia) $106-8 \mathrm{Mgt}$, obtido por Millardet e de Grasset, na França, em 1882. Apresenta enraizamento das estacas satisfatório, é resistente à filoxera, mas é suscetível à antracnose; contudo, possui resistência à seca. Embora não muito vigoroso, adapta-se bem a muitos tipos de solo, inclusive aos ácidos. É compatível com videiras 'Niágara', motivo pelo qual é um dos mais difundidos no Estado de São Paulo. Também é compatível com as cultivares Patrícia, Soraya e Paulistinha (Pommer et al., 1997; Simão, 1998).

'Schwarzmann': é um híbrido natural resultante do cruzamento entre $V$. riparia e V. rupestris, selecionado por Bizenz. Apresenta vigor médio e satisfatório enraizamento, é adaptado a terrenos secos, áridos, ácidos e arenosos (Sousa, 1996). Revela boa resistência a nematóides (Stirling \& Cirami, 1984). Embora seja pouco difundido, é apropriado para as condições paulistas, podendo ser uma opção para a cultivar Niágara (Pommer et al., 1997).
O delineamento experimental adotado foi o quadrado latino de cinco linhas e cinco colunas, com cinco repetições e seis plantas por parcela.

As seguintes variáveis foram determinadas: a) produção média por planta ( $\mathrm{kg} / \mathrm{planta})$ : os cachos colhidos por parcela foram pesados e foi calculada a produção média por planta. Essa variável foi medida durante todo o período experimental (safras 90/91 a 97/98); b) número de cachos colhidos por planta: nas safras $96 / 97$ e $97 / 98$ foi contado o número de cachos colhidos por parcela e calculada a média por planta; c) massa de ramos podados (g/planta): após a poda de inverno foram pesados os ramos eliminados em cada parcela, e calculada a média por planta. Essa variável foi determinada nas safras 96/97 e 97/98.

Os dados coletados foram submetidos a análise de variância (teste F) e comparação múltipla de médias pelo teste de Tukey a 5\% de probabilidade.

\section{Resultados e Discussão}

Os porta-enxertos 'IAC 313' e 'IAC 766', de maneira geral, induziram maiores produções por planta (Tabela 1). A produção média por planta ao final dos oito anos de avaliação dos porta-enxertos 'IAC 313' e 'IAC 766' foi maior do que a dos porta-enxertos 'Kober 5BB' e 'Schwarzmann', mas não diferiu estatisticamente do 'Traviú'. Este, por sua vez, não diferiu do porta-enxerto 'Schwarzmann'.

Os resultados referentes à produção média nos porta-enxertos 'IAC 313' (2,69 kg/planta) e 'IAC 766' (2,59 kg/planta) são semelhantes aos verificados por Abrahão et al. (1996), que obtiveram $2,69 \mathrm{~kg} /$ planta e $2,57 \mathrm{~kg} /$ planta em relação a esses dois porta-enxertos utilizados na cultivar Folha-defigo (Vitis labrusca L.), nas condições de Caldas. Entretanto, contrariam os resultados obtidos por Terra et al. (1988) com relação ao porta-enxerto 'Schwarzmann', cuja produção foi de 3,11 kg/planta na videira 'Niágara Rosada', nas condições de Jundiaí.

As produções por planta sofreram oscilações, alternando boas com fracas produções. Isso é explicado pelo fato de que a indução floral, ou seja, a indução das células para primórdio do cacho ocorre nas primeiras semanas depois que um nó se separa de um ápice. O primórdio de cacho continua a se desenvolver em tamanho e complexidade por oito a doze semanas, coincidindo com o desenvolvimento do cacho do ciclo corrente. Nesse estádio, o número total 
de flores potenciais para a colheita seguinte já foi determinada. Assim, por exemplo, o potencial máximo de produção para a safra $93 / 94$ foi determinado no início da safra 92/93, e assim sucessivamente (Kliever, 1990). Portanto, a presença de grande carga de frutos em uma determinada safra tende a reduzir a indução e a diferenciação floral responsáveis pelo potencial produtivo da próxima safra, caracterizando a alternância de produção. Tem sido relatado também que a presença de um grande número de frutos reduz a indução floral pela alta concentração de giberelina, presente, principalmente, nas sementes (Faust, 1989; Mullins et al., 1992).

No presente trabalho, a alternância de produção foi mais evidente nas combinações mais produtivas do que nas menos produtivas. As baixas produções nos biênios 95/96 e 96/97 deveu-se, provavelmente, à deficiência de boro, diagnosticada em 1995. Posteriormente, com a correção do nutriente via solo, a produção voltou a crescer.

A produtividade estimada nos diferentes tratamentos foi de 8,$96 ; 8,63 ; 6,63 ; 4,13$ e 3,96 t/ha, em relação aos porta-enxertos 'IAC 313', 'IAC 766', 'Traviú', 'Schwarzmann' e 'Kober 5BB', respectivamente, o que revela uma superioridade de produtividade em mais de $100 \%$ dos dois primeiros portaenxertos em relação aos dois últimos. A superioridade em produtividade do 'IAC 313' e do 'IAC 766' sobre o 'Kober 5BB' também foi verificada por outros autores (Martins et al., 1981; Abrahão et al., 1996;
Gonçalves, 1996). O 'Traviú' apresentou comportamento intermediário, não diferindo estatisticamente dos porta-enxertos 'IAC 313', 'IAC 766' e 'Schwarzmann'. O 'Traviú' revelou produtividade cerca de $25 \%$ menor que os dois porta-enxertos mais produtivos.

O número de cachos colhidos, por planta, foi determinado nas safras 96/97 e 97/98 (Tabela 2). De maneira geral, o 'Kober 5BB' produziu menor número de cachos, enquanto os maiores foram obtidos no 'IAC 313', 'IAC 766' e 'Traviú', na safra 97/98, e no 'IAC 313', 'IAC 766' e 'Schwarzmann', na safra 97/98. Resultados que explicam, em parte, as superiores produções observadas no 'IAC 313' e 'IAC 766'.

O porta-enxerto 'IAC 766' apresentou o maior volume de material podado, seguido do 'IAC 313' (Tabela 3). Na safra 96/97, o 'IAC 766' mostrou diferença estatística em relação ao 'Kober 5BB', enquanto na safra 97/98 revelou diferença significativa em relação ao 'Traviú' e ao 'Schwarzmann'. A maior massa de ramos podados indica maior crescimento da parte aérea no ano anterior. Assim, ficou demonstrado que existe diferença de vigor entre os porta-enxertos, refletido principalmente pela massa de ramos retirados na poda de inverno.

As variações encontradas nas medidas relacionadas com a produção e o vigor estão associadas, provavelmente, com as diferentes interações que ocorreram entre a copa e os porta-enxertos testados. Tem

Tabela 1. Produção da videira 'Niágara Rosada' em diferentes porta-enxertos. Taubaté, SP, 1990-1997(1).

\begin{tabular}{|c|c|c|c|c|c|c|c|c|c|}
\hline \multirow[t]{2}{*}{ Porta-enxerto } & \multicolumn{8}{|c|}{ Safra } & \multirow[t]{2}{*}{ Média } \\
\hline & $90 / 91$ & $91 / 92$ & $92 / 93$ & $93 / 94$ & $94 / 95$ & $95 / 96$ & $96 / 97$ & $97 / 98$ & \\
\hline & & & & & (kg/plant & a) --.---- & & & \\
\hline 'IAC 313' & $1,21 \mathrm{ab}$ & $0,87 \mathrm{a}$ & $2,95 \mathrm{a}$ & $1,05 \mathrm{a}$ & $6,21 \mathrm{a}$ & $2,21 \mathrm{a}$ & $0,94 \mathrm{ab}$ & $6,10 \mathrm{a}$ & $2,69 \mathrm{a}$ \\
\hline 'IAC 766’ & $1,89 \mathrm{a}$ & $1,11 \mathrm{a}$ & $3,12 \mathrm{a}$ & $1,58 \mathrm{a}$ & $4,94 \mathrm{ab}$ & $2,18 \mathrm{a}$ & $1,15 \mathrm{a}$ & $4,81 \mathrm{ab}$ & $2,59 \mathrm{a}$ \\
\hline 'Kober 5BB' & $0,63 b$ & $0,87 \mathrm{a}$ & $1,42 b$ & $1,13 \mathrm{a}$ & $0,66 \mathrm{c}$ & $1,29 \mathrm{ab}$ & $0,48 b$ & $3,03 \mathrm{~b}$ & $1,19 \mathrm{c}$ \\
\hline ‘Traviú' & $1,63 \mathrm{ab}$ & $0,84 a$ & $2,76 \mathrm{ab}$ & $1,23 \mathrm{a}$ & $3,11 b c$ & $1,64 \mathrm{ab}$ & $1,04 \mathrm{ab}$ & $3,67 b$ & $1,99 \mathrm{ab}$ \\
\hline 'Schwarzmann' & $0,66 b$ & $0,98 \mathrm{a}$ & $2,07 \mathrm{ab}$ & $1,20 \mathrm{a}$ & $1,28 \mathrm{c}$ & $0,84 b$ & $0,44 b$ & $2,84 \mathrm{~b}$ & $1,24 \mathrm{bc}$ \\
\hline $\mathrm{F}$ (tratamentos) & $3,97^{*}$ & $0,29^{\text {ns }}$ & $3,92^{*}$ & $1,05^{\mathrm{ns}}$ & $10,53^{* *}$ & $3,76^{*}$ & $3,13^{*}$ & $5,41^{\text {*** }}$ & $12,46^{* *}$ \\
\hline d.m.s. & 1,06 & 0,78 & 1,35 & 0,73 & 2,74 & 1,14 & 0,69 & 2,20 & 0,74 \\
\hline C.V. $(\%)$ & 22,69 & 19,80 & 32,50 & 35,42 & 20,17 & 21,50 & 20,93 & 31,96 & 22,23 \\
\hline
\end{tabular}

${ }^{(1)}$ Médias seguidas de mesma letra, na coluna, não diferem entre si pelo teste de Tukey a 5\% de probabilidade. ${ }^{\text {ns }}$ Não-significativo. Significativo a 5\% de probabilidade. ${ }^{* *}$ Significativo a $1 \%$ de probabilidade. 
sido relatado que, para cada combinação copa/porta-enxerto, existe um equilíbrio fisiológico ou grau de afinidade que influencia o crescimento e a produção (Zuluaga, 1943; Gonçalves, 1996). Esse equilíbrio, segundo Hartmann \& Kester (1990), é resultante de mecanismos de reciprocidade entre o portaenxerto e a copa, envolvendo a absorção e translocação de água e nutrientes e fatores endógenos de crescimento. Normalmente, os porta-enxertos mais vigorosos apresentam maior capacidade de absorção e translocação de água e nutrientes, e maior produção de substâncias estimuladoras de crescimento, o que favorece o desempenho da copa.

O maior crescimento da copa não implica necessariamente maior produção. Hartmann \& Kester (1990) comentaram que o uso de porta-enxertos vigorosos na videira geralmente aumenta a produtividade, mas em alguns casos, os porta-enxertos vigorosos podem reduzir drasticamente a produção, quando utilizados em condições ótimas de clima e solo, conforme os autores verificaram no porta-enxerto 'Dog Ridge' (V. champinni), considerado muito vigoroso. Por outro lado, o crescimento limitado da copa não conduz obrigatoriamente a uma baixa produção. Southey \& Fouché (1990), utilizando o porta-enxerto 'RR 101-14' em videira 'Chenin Blanc', obtiveram pouco crescimento da planta, conseguindo, ainda assim, uma alta produção.

Portanto, os efeitos do porta-enxerto não são passíveis de serem detectados sem considerar o sistema

Tabela 2. Número de cachos colhidos por planta da videira 'Niágara Rosada' em diferentes porta-enxertos. Taubaté, SP, 1996-1997(1).

\begin{tabular}{lcc}
\hline Porta-enxerto & Safra 96/97 & Safra 97/98 \\
\hline 'IAC 313' & $12,64 \mathrm{a}$ & $34,60 \mathrm{a}$ \\
'IAC 766' & $11,26 \mathrm{ab}$ & $30,80 \mathrm{ab}$ \\
'Kober 5BB' & $6,35 \mathrm{~b}$ & $21,60 \mathrm{~b}$ \\
'Traviú' & $12,19 \mathrm{a}$ & $24,20 \mathrm{ab}$ \\
'Schwarzmann' & $8,06 \mathrm{ab}$ & $30,00 \mathrm{ab}$ \\
\hline F (tratamentos) & $3,67^{*}$ & $3,65^{*}$ \\
d.m.s. & 5,82 & 11,05 \\
C.V. $(\%)$ & 4,22 & 23,20 \\
\hline
\end{tabular}

(1) Médias seguidas de mesma letra, na coluna, não diferem entre si pelo teste de Tukey a $5 \%$ de probabilidade. Significativo a $5 \%$ de probabilidade. como um todo (copa/porta-enxerto), uma vez que existe ação recíproca entre as partes envolvidas. Hartmann \& Kester (1990) salientaram que quando se utiliza copa vigorosa em porta-enxerto pouco vigoroso, este pode apresentar o sistema radicular mais desenvolvido, ao passo que um porta-enxerto vigoroso pode apresentar menor sistema radicular quando sobre ele é enxertada uma copa pouco vigorosa. Além disso, cada combinação sofre influência das condições de clima e solo, o que pode modificar completamente a resposta.

No presente experimento o ciclo de produção (poda-colheita) variou entre 139 e 145 dias, quando a poda foi realizada na primeira semana de agosto. Assim, a época de colheita foi antecipada em 15 dias, em média, com relação à época de colheita das regiões tradicionais. Verificou-se, através dos resultados de volume de poda e observações de campo, que os porta-enxertos 'IAC 766' e 'IAC 313' trouxeram maior vigor à copa do que o 'Kober 5BB' e 'Schwarzmann', e este maior vigor induziu maior produção, indicando, assim, uma melhor combinação da cultivar estudada com os dois primeiros em relação aos dois últimos. Assim, infere-se que os porta-enxertos mais indicados para a região e para a cultivar Niágara Rosada são o 'IAC 313', o 'IAC 766' e o 'Traviú'. Esses porta-enxertos confirmaram o bom desempenho verificado em ensaios de competição de porta-enxertos de videira (Scaranari et al., 1975; Martins et al., 1981; Terra et al., 1989, 1990b;

Tabela 3. Massa dos ramos podados da videira 'Niágara Rosada' em diferentes porta-enxertos. Taubaté, SP, 1996-1997(1).

\begin{tabular}{lcc}
\hline Porta-enxerto & Safra 96/97 & Safra 97/98 \\
\hline & ------------ \\
'IAC 313' & $692,40 \mathrm{ab}$ & $120,88 \mathrm{ab}$ \\
'IAC 766' & $794,60 \mathrm{a}$ & $156,40 \mathrm{a}$ \\
'Kober 5BB' & $449,00 \mathrm{~b}$ & $111,15 \mathrm{ab}$ \\
'Traviú' & $598,80 \mathrm{ab}$ & $81,75 \mathrm{~b}$ \\
'Schwarzmann' & $510,00 \mathrm{ab}$ & $73,74 \mathrm{~b}$ \\
\hline F (tratamentos) & $3,56^{*}$ & $5,47^{*}$ \\
d.m.s. & 286,24 & 53,30 \\
C.V. (\%) & 28,17 & 29,07 \\
\hline \multirow{2}{*}{ (1) Médias seguidas de mesma letra, na coluna, não diferem entre si pelo } \\
teste de Tukey a 5\% de probabilidade. Significativo a 5\% de probabili- \\
dade.
\end{tabular}

Pesq. agropec. bras., Brasília, v. 36, n. 1, p. 115-121, jan. 2001 
Abrahão et al., 1996). As indicações desses portaenxertos para esta cultivar podem ser extrapoladas para outras regiões, desde que haja similaridade de condições de clima e solo. Para condições diferentes, são requeridos testes de competição de portaenxertos para identificar as melhores combinações.

\section{Conclusão}

Os porta-enxertos mais indicados para videira 'Niágara Rosada' cultivada no Município de Taubaté, no Vale do Paraíba, SP, são o 'IAC 313', o 'IAC 766' e o 'Traviú', e os não-indicados, o 'Kober 5BB' e o 'Schawarzmamm'.

\section{Referências}

ABRAHÃO, E.; ALVARENGA, A. A.; CHALFUN, N. N. J.; REGINA, M. A. Efeito de diferentes porta-enxertos na produção de uvas da cultivar Folha de Figo. Revista Brasileira de Fruticultura, Cruz das Almas, v. 18, n. 3, p. 367-370, 1996.

EDWARDS, M. Effects of the type of rootstock on yields of Catarina grapevines (Vitis vinifera) and levels of citrus nematode (Tylenchulus semipenetrans Coob.). Australian Journal of Experimental Agriculture, Collingwood, v. 28 , n. 2, p. 283-286, 1988.

FAUST, M. Physiology of temperate zone fruit trees. New York : J. Wiley, 1989. 338 p.

GONÇALVES, C. A. A. Comportamento da cultivar Folha de Figo (Vitis labrusca L.) sobre diferentes porta-enxertos de videira. Lavras : UFLA, 1996. 45 p. Dissertação de Mestrado.

GONÇALVES, C. A. A.; REGINA, M. A.; CHALFUN, N. N. J.; ALVARENGA, A. A; ABRAHÃO, E.; BERZOTI, E. Comportamento da cultivar Folha de Figo (Vitis labrusca L.) sobre diferentes porta-enxertos de videira. Revista Brasileira de Fruticultura, Cruz das Almas, v. 21, n. 1, p. 7-11, 1999.

HARTManN, H. T.; KeSTER, D. E. Propagación de plantas: principios y practicas. México : Continental, 1990. $760 \mathrm{p}$.

HIDALGO, L. Tratado de viticultura general. Madrid : Mundi-Prensa, 1993. 983 p.

KLIEVER, W. R. Fisiologia da videira: como produz açúcar uma videira? Campinas: Instituto Agronômico, 1990. 20 p. (IAC. Documentos, 20).
MARTINS, P. F.; SCARANARI, J. H; RIBEIRO, A. J. I.; TERRA. M. M.; IGUE, T.; PEREIRA M. F. Valor comparativo de cinco porta-enxertos para cultivo de uva de mesa Patrícia (IAC 871-41). In: CONGRESSO BRASILEIRO DE FRUTICULTURA, 6., 1981, Recife. Anais... Recife : Sociedade Brasileira de Fruticultura, 1981. v. 4, p. $1300-1310$.

MULLINS, M. G.; BOUQUET, A.; WILLIAMS, L. E. Biology of grapevine. Cambridge, Grã-Bretanha : Cambridge University Press, 1992. 239 p.

NOGUEIRA, D. J. P. Porta-enxertos de videira. Informe Agropecuário, Belo Horizonte, v. 10, n. 117, p. 22-24, 1984.

PASTENA, B. Tratado de viticultura italiana. 2. ed. Bolonha : Edagrícola, 1981. 1011 p.

POMMER, C. V.; PASSOS, I. R. S.; TERRA, M. M.; PIRES, E. J. P. Variedades de videira para o Estado de São Paulo. Campinas : Instituto Agronômico, 1997. 59 p. (IAC. Boletim Técnico, 166).

SANTOS NETO, J. R. A. A cultura da videira. Campinas : Instituto Agronômico, 1973. 108 p.

SCARANARI, H. J.; MARTINS, F. P.; IGUE, T. Ensaio de porta-enxertos para a variedade de uva para vinho Seyve Villard 5276. Bragantia, Campinas, v. 34, n. 1, p. 15-18, 1975.

SIMÃO, S. Tratado de fruticultura. Piracicaba : FEALQ, 1998. $760 \mathrm{p}$.

SOUSA, J. S. I. de. Uvas para o Brasil. 2. ed. Piracicaba : FEALQ, 1996. $791 \mathrm{p}$.

SOUTHEY, T. M.; FOUCHÉ, G. W. The performance of 'Chenin blanc' grafted onto different rootstock cultivars on a Dundee soil in the Montager district. South African Journal of Enology and Viticulture, Stellembosch, v. 11, n. 1, p. 50-54, 1990.

STIRLING, G. R.; CIRAMI, R. M. Resistance and tolerance of grape rootstocks to South Australian populations of root-knot nematode. Australian Journal of Experimental and Animal Husbandry, Collingwood, v. 24, n. 3, p. 277-282, 1984.

TERRA, M. M.; MARTINS, F. P.; PIRES, E. J. P.; POMMER, C. V.; PASSOS, I. R. S.; RIBEIRO, I. J. A.; COELHO, S. M. B. M.; SILVA, A. C. P. Cultivares IAC de uva Moscatel para vinho sobre diferentes porta-enxertos. In: CONGRESSO BRASILEIRO DE FRUTICULTURA, 10. , 1989, Fortaleza. Anais... Fortaleza : Sociedade Brasileira de Fruticultura, 1989. p. 462-466. 
TERRA, M. M.; PIRES, E. J. P.; COELHO, S. M. B. M.; PASSOS, I. R. S.; SANTOS, R. R. D.; POMMER, C. V.; SILVA, A. C. P.; RIBEIRO, I. J. A. Rootstocks for the wine grape cultivar 'Máximo' - IAC 138-22 in Monte Alegre do Sul, SP. Bragantia, Campinas, v. 49, n. 2, p. 363-369, 1990a.

TERRA, M. M.; PIRES, E. J. P.; PETTINELLI, A. J. R.; POMMER, C. V.; SABINO, J. C.; PASSOS, I. R. S.; COELHO, S. M. B. M.; SILVA, A. C. P.; RIBEIRO, I. J. A. Productivity of own rooted and grafted IAC wine grape cultivars on different rootstocks. Bragantia, Campinas, v. 49 , n. 2 , p. $345-362,1990$ b.
TERRA, M. M.; POMMER, C. V.; ERASMO, P.; PASSOS, L. R. S.; MARTINS, F. P.; RIBEIRO, J. J. A. Comportamento de porta-enxertos para o cultivar de uva de mesa Niágara Rosada em Jundiaí, SP. In: CONGRESSO BRASILEIRO DE FRUTICULTURA, 9. , 1987, Campinas. Anais... Campinas : Sociedade Brasileira de Fruticultura, 1988. p. 721-725.

ZULUAGA, A. P. Consideraciones sobre afinidad de variedades viníferas com porta-enjertos americanos. Mendoza : Faculdad de Ciencias Agrarias, 1943. 34 p. (Boletín Técnico, 2). 